\title{
COVID-19 Pandemic-What Should Not Be Forgotten
}

\author{
Luca Koechlin ${ }^{1}$ \\ ${ }^{1}$ Department of Cardiac Surgery, University Hospital Basel, Basel, \\ Switzerland \\ Thorac Cardiovasc Surg Rep 2021;10:e31-e35.
}

\begin{abstract}
Address for correspondence Luca Koechlin, MD, Department of Cardiac Surgery, University Hospital Basel, Spitalstrasse 21, CH-4031 Basel, Switzerland (e-mail: luca.koechlin@usb.ch).
\end{abstract}

\begin{abstract}
The Swiss Society of Cardiac Surgery (SGHC) has announced a "Special Swiss Young Cardiac Surgeon Award 2020," with the aim to learn more about the consequences of Keywords

- cardiac

- cardiovascular surgery

- education

- level the coronavirus disease 2019 (COVID-19) pandemic for young Swiss cardiac surgeons. Therefore, the overall goal of this article is to highlight the personal situation and perspective of a young Swiss cardiac surgeon in training during the COVID-19 pandemic. This article reflects the personal opinion of a young Swiss cardiac surgeon discussing the impact of the pandemic for young surgeons in training and potential chances and learning effects.
\end{abstract}

\section{Introduction}

When the first reports on the coronavirus disease 2019 (COVID-19), caused by severe acute respiratory syndrome coronavirus 2 , were published, very few expected that this would become the "biggest crisis within the postwar period" (Giuseppe Conte, Prime Minister of Italy). ${ }^{1}$

Within just a few weeks, COVID-19 had spread all over the world and was declared a pandemic by the World Health Organization on March 11, 2020, the first since the H1N1 2009/2010 pandemic. $^{2}$

Besides its impact on the health care systems and on the health of hundred thousands of people, the subsequent "lockdown" introduced in most countries worldwide, and consequently, implemented measures, such as social distancing, have led to immense restrictions in everyone's daily life as well as to a devastating economical aftermath. It can further be assumed that a major part of the effects will only become apparent in the near and more distant future. Moreover, no one knows right now (May 2020) how this pandemic will influence our future behavior and the society as a whole, or if a so-called second wave will arise.

As a matter of fact, the health care systems, and especially nurses and doctors, played essential roles during this crisis.
While experts, politicians, and the media were constantly issuing bylaws and warning the community, nurses and doctors were taking care of numerous patients under most challenging conditions.

Switzerland was affected to an extent that was so far unknown; to the present day, we have more than 30,500 confirmed cases and more than 1,800 deaths (see https:// coronavirus.jhu.edu/map.html; May 18, 2020).

Since these impacts also have drastic consequences for the young doctors in Switzerland who are not the focus of public interest, the Swiss Society of Cardiac Surgery (SGHC) has announced a "Special Swiss Young Cardiac Surgeon Award 2020," with the aim to learn more about the consequences of this pandemic for young Swiss cardiac surgeons.

Therefore, the overall goal of this article is to highlight the personal situation and perspective of a young Swiss cardiac surgeon in training during the COVID-19 pandemic, and to discuss potential chances and learning effects.

\section{The Change in Daily Practice}

Besides the measures and recommendations implemented by the Federal Council of Switzerland for the general received

September 3, 2020

accepted

September 11, 2020
DOI https://doi.org/

10.1055/s-0040-1721024. ISSN 2194-7635.

\footnotetext{
(C) 2021. The Author(s).

This is an open access article published by Thieme under the terms of the Creative Commons Attribution-NonDerivative-NonCommercial-License, permitting copying and reproduction so long as the original work is given appropriate credit. Contents may not be used for commercial purposes, or adapted, remixed, transformed or built upon. (https://creativecommons.org/ licenses/by-nc-nd/4.0/) Georg Thieme Verlag KG, Rüdigerstraße 14, 70469 Stuttgart, Germany
} 
population, such as social distancing, closing of borders, and new hygiene rules, hospital-specific measures had direct and immediate consequences for the daily practice in Swiss hospitals, and especially in the departments of cardiac surgery. ${ }^{3}$ Elective surgeries were postponed, and only urgent or salvage operations were approved to be performed. Since cardiac surgery departments, among all surgical disciplines, have the greatest need for intensive care unit (ICU) beds and the number of available ICU beds represented a critical factor during the pandemic, many departments of cardiac surgery have already reduced their operations program before the official decree by the Federal Council of Switzerland.

In addition, hospital-intern measures also directly impact(ed) the daily practice, especially that of the residents. Several reorganization and emergency plans were established, and among the doctors, mostly residents were assigned to be part of these plans. The fact that residents and not the more experienced consultants, whose expertise in their specialty was tried to remain preserved, were chosen to be transferred to work in the emergency department or in the ICU to test or treat COVID-19 patients, is reasonable. However, these measures had immediate consequences for the affected colleagues. Besides an immense expected flexibility (demands for reassignment of the working areas, e.g., shifts in the ICU, were announced only 48 hours in advance), one was suddenly faced with patients whose treatment varied widely from the treatment of patients of one's chosen specialty field. Furthermore, one was exposed to the risk of infection, even though all hospitals made constant efforts to stress the highest priority was the protection of their staff. Apart from that, constantly changing rules regarding holidays, from forced holidays to a complete holiday lock, required additional flexibility.

But the most drastic change, at least from my viewpoint as a young cardiac surgeon in training, was the consequently reduced time in the operating room and thus decreased chances to be trained. Achieving the necessary number of operations that have to be performed to be admitted to the board examination represents the biggest hurdle to overcome, even under normal circumstances-the COVID-19 pandemic has greatly intensified this problem. Since only urgent and emergency operations were allowed to be performed, the number of "teaching cases" decreased. Even worse off were colleagues who had been transferred to other departments, as their chances to participate in operations were nil.

Last but not least, all further training courses and congresses, normally a substantial part of the training and education, had been canceled.

\section{Relevance for the Field "Cardiac Surgery"}

While on first sight, one would not expect that cardiac surgery is a key player in the treatment of patients who are affected by COVID-19, which is an infectious disease, cardiac surgeons and cardiac surgery societies were present in the media in various ways.

During the COVID-19 pandemic, a decrease in patients admitted with ST-segment elevation myocardial infarction, and therefore emergencies for cardiologists and cardiac surgeons, was observed. ${ }^{4,5}$ As one possible explanation for this was that the people avoided emergency departments in fear of becoming infected, several societies made public efforts addressing people with heart problems. ${ }^{6,7}$ The "Deutsche Gesellschaft für Kardiologie - Herz- und Kreislaufforschung (DGK)," "Deutsche Gesellschaft für Thorax-, Herz- und Gefäßchirurge (DGTHG)," "Deutsche Gesellschaft für Pädiatrische Kardiologie und Angeborene Herzfehler (DGPK)," and the "Deutsche Herzstiftung" very early wrote an open letter to Anja Karliczek, the Federal Minister of Education and Research in Germany, stressing the importance of patients presenting themselves to an emergency department in case of chest pain, as well as the importance of the performance of urgent cardiac operations. ${ }^{7}$ And Prof. Falk, Medical Director of the "Deutsches Herzzentrum Berlin," directly addressed the 2,411 Instagram followers of the "Deutsches Herzzentrum Berlin" with the appeal not to hesitate to present themselves to the emergency department in case of cardiac symptoms. ${ }^{8}$ And also in Switzerland, campaigns were initiated to draw attention to the public to not neglecting cardiac symptoms, as for example, Prof. Englberger did for the Hirslanden Group. ${ }^{9}$ However, I missed an early and clear communication from the government regarding this important issue.

Furthermore, already at the end of March 2020, Profs. Matt and Maisano published an article regarding the consequences for the cardiac surgery community, and the "Society of Thoracic Surgeons" (STS) and the "Canadian Society of Cardiac Surgeons" provided guidance statements. ${ }^{10-12}$

One article, published by Prof. Vogt, a cardiac surgeon, criticizing strategies and measures by the Federal Council of Switzerland, ${ }^{13}$ has attracted huge attention (more than 350,000 reads within 2 days) and was discussed very controversially in Switzerland.

However, even if several cardiac surgery societies attribute an "active leadership role on the health care team during this pandemic"12 to cardiac surgeons, and even though cardiac surgeons should "offer leadership services" to hospitals and communities, ${ }^{11}$ they were not broadly integrated in the development of the COVID-19 treatment strategies, at least as far as my personal experience goes. This may surprise, especially since extracorporeal membrane oxygenation (ECMO) represents one possible strategy to treat the most severe COVID-19 cases that suffer from the acute respiratory distress syndrome. Mid of May 2020, more than 1,100 ECMOs were used due to COVID-19 in Europe. ${ }^{14-16}$ Cardiac surgeons provide a huge experience with the ECMO treatment. Nonetheless, it seems like a chance was missed and they were only rarely involved in the development of ECMO therapy strategies. For me and my colleagues, gaining experience with ECMO therapy is a crucial part of our education, and an active involvement of cardiac surgery departments in this topic would have been beneficial for educational reasons, too.

\section{What Would Have Helped}

Regarding clinical training, the COVID-19 pandemic had a strong yet potentially precarious impact on young surgeons 
like me. It has, to a certain extent, set us back in our clinical training in the operating room.

While those transferred to the emergency department or to the ICU were entirely banned from the operating room, the remaining residents at cardiac surgery departments were confronted with a reduced number of operations-the remaining operations were mostly urgent, and emergency operations are often not suitable for training. This can have immediate consequences for us young surgeons. While for the majority, this means an only roughly assessable setback in their training, some of us are targeted on the board examination (Membership of the European Board of Cardiothoracic Surgery [MEBCTS]) at the upcoming annual meeting of the European Association for Cardio-Thoracic Surgery (EACTS), planned in Barcelona, Spain, from October 8 to October 10, 2020. To be accepted to the MEBCTS, which is a prerequisite to be admitted to the Swiss board examination, one has to have performed a minimum number of operations. There is a considerable risk that some of the candidates will have difficulties achieving their required number of operations.

On the other side, some of the residents were obliged to take compensation days or holidays. While the residents who were assigned to a research fellowship or project during the time with the reduced operation numbers had the opportunity to push forward their research projects (even if some basic research institutes had to close, and home office directives were implemented also in clinical research), possibilities for practical training during this time were scarce. For me personally and my training, the pandemic had a significant impact. Being in my second year in cardiac surgery training after completing the common trunk, 6 months on the ICU, and after a 1-year research fellowship (and therefore aspiring for surgical training), I found myself on a "shortlist" for the ICU in case they needed more staff (with an announcement 48 hours in advance). Furthermore, the reduced operation numbers had limited opportunities for surgical training in the operating room. However, I was able to use the unexpectedly available time to push forward some research projects.

The value of simulator training in (cardiac) surgery has been the subject of discussion for many years. Also, with the "Swiss Academy," the SGHC introduced a simulator-based training for cardiac surgery. However, during the COVID-19 pandemic, these courses, as well as the courses by the EACTS (which are considered helpful for the preparation for the MEBCTS) and the DGTHG, could not be performed. This shows the urgent need for training facilities which are local and easily accessible. While this has already been the subject of discussion before the pandemic (e.g., to provide young surgeons with a local opportunity to deepen their skills they have learnt at centralized courses), facilities like these would provide the opportunity for tutored, but also for independent trainings.

On the other side, webinars, which have already gained popularity before the pandemic, were numerously offered during the pandemic, but were probably only rarely attended. However, the technical progress has created new possibilities. Social media, especially Twitter as a tool for continued medical education, has gained popularity during the COVID-19 pandemic and should be part of future thoughts on how to organize and structure training possibilities. ${ }^{17}$

Communicating learning contents in a centralized manner, organized by the SGHC, would have several benefits. For instance, teaching operation techniques and strategies would open up the opportunity for young trainees to learn the techniques as applied in their clinics. On the other side, the SGHC would have the opportunity to educate and train the young Swiss cardiac surgeons in their routine, which is also a goal of the "Swiss Academy." Such an online library, providing operation videos, techniques, and theoretical knowledge, could perfectly complement the practical courses of the "Swiss Academy." Furthermore, a learning program of this kind could be used independently of any outside influence, like a pandemic. The lower operation numbers in cardiac surgery in general and the associated pitfalls in clinical training have been discussed for years. But in such extraordinary times (and nobody knows for how long this will last, and if we will be confronted with a similar situation in the next year), further strategies that provide structured clinical training to the young Swiss cardiac surgeons are urgently needed.

\section{Asking the Right Questions}

Once we have overcome the COVID-19 pandemic and have found our way back to normality, whatever that will mean, we must critically analyze and reflect the measures and strategies implemented during the pandemic. While certain groups already make their demands, the medical society, nurses as well as doctors, must be involved in the public discussion and should be enabled to state their claims, especially regarding protection and compensation. Therefore, I hope and expect that some basic questions will be discussed very carefully. Questions that have formed in my mind on the basis of my personal experiences as a young cardiac surgeon during this pandemic are as follows:

1. On what legal basis were reorganizations and emergency plans established and employment laws suspended?

2. How is the medical staff, nurses and doctors, compensated for their extraordinary flexibility, extended working hours, and self-endangerment that goes way beyond of what can normally be expected?

3. Why were, from a certain time point onward, all patients in the hospital tested for COVID-19, but not the medical staff?

4. How well are we prepared for a potential second wave in autumn, or another pandemic?

I strongly believe that it is important that these and other questions are asked and hopefully being answered by the responsible authorities and professional experts. Furthermore, I am convinced that it will be important that the health care employees stand together, speak and act as one unit, and are not separated into doctors or nurses who discretely stand up for their own rights, wherethrough joint interests and objectives fall into oblivion. I think that the professional societies, such as the SGHC, also have a responsibility to stand up for the rights of their members, and they should 
look out for collaborations with other societies, and increase political pressure, as Swiss politicians seem prepared to talk about improvements of the conditions of employment of people with system-relevant professions. ${ }^{18}$ However, current movements suggest that the health care system, once again, will not fight unitedly, but separately. ${ }^{19}$

\section{What Should Not Be Forgotten}

The COVID-19 pandemic affected all of us in different, however in most cases drastic, ways. Yet, the mistake of returning to normality as soon as possible must be avoided. We have to learn a sustainable lesson from this crisis, and this should be adequately emphasized.

First, on a national level, the value and dependability of our national health care system were central, and also appreciated by the public in Switzerland and all over the world, highlighted by different campaigns. ${ }^{20,21}$ Although these are great gestures by the public, by celebrities, or politicians, important issues such as compensation adjustments, coworker protection, and adequate future emergency plans must be part of an after crisis debate, and not be forgotten.

Second, on a hospital level, residents in several clinics were key players in emergency and reorganization plans, and an extraordinary flexibility regarding their working conditions was demanded of them. This must be valued. Especially in surgical specialties, it must be emphasized that valuable time for clinical training and the opportunities to achieve the necessary numbers of operations were lost.

Third, the extra flexibility that was demanded of residents must be taken into consideration and recognized by the societies. Individual cases must be examined, for example, regarding the demanded minimal operation numbers to be admitted to the MEBCTS examination. Since Switzerland is one of the few countries in which the MEBCTS is mandatory to be accepted for the board examination by the SGHC and therefore the Swiss board certification, no candidate should lose 1 entire year because of the fact that, due to the COVID-19 pandemic, operation numbers were limited. This may also require negotiations with the EACTS regarding the admission requirements for the MEBCTS, and the development of new strategies in case the annual meeting of the EACTS and the MEBCTS should be postponed.

Fourth, there is a need for concrete plans that determine how things such as operation numbers are to be handled if the crisis continues or a "second wave" hits us within the next year.

\section{Think Outside the Box}

The COVID-19 pandemic has confronted everyone with existential issues. Not only are we challenged with the fact that the "normality" we were used to will not exist anymore, at least for a very long time to come. We as doctors are faced with new challenges. Perhaps, this pandemic helps us reconsider what being a doctor means to us. For once, not the highly specialized disciplines (neurosurgery, cardiac surgery, and so on), which normally are often in the spotlight, are leading. Confronted with a virus, with which we as surgeons do not have any experience, we realize that we are not as powerful and capable to help patients as we were used to, as for example in an operating room operating bypasses and valves. But what is the purpose of being a doctor? What is the aim of medicine? "Guérir quelquefois, soulager souvent, consoler toujours" "to cure sometimes, to relieve often, to comfort always." 22 Even if in the public expectation, and also in the light of interclinic concurrence, healing is claimed to be the overarching goal of being a doctor, this pandemic has taught me that we also have to accept that caring is at least an equipollent cornerstone of a

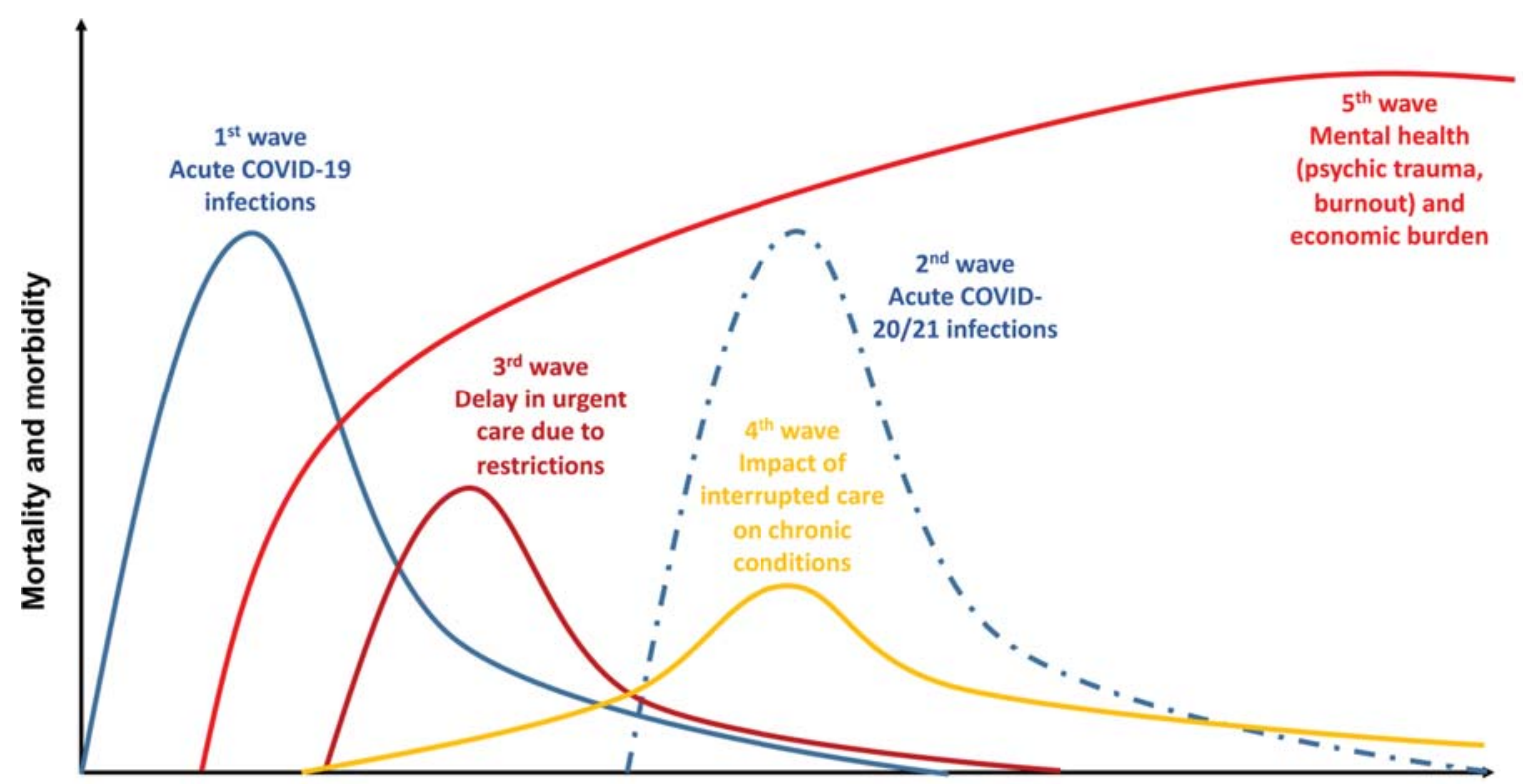

Time

Fig. 1 Different waves of the COVID-19 pandemic. 
physician's responsibility. And this is exactly what can be accomplished by all doctors and health care employees during this time, even if we are not specialists in the field of COVID-19. This is of great importance considering the long course of this pandemic. While everyone is aware of and talking about the first and second waves of this pandemic, the third, fourth, and fifth waves are for sure underestimated (-Fig. 1). While the respective societies will be (and have to be!) endeavored to reduce the impact of interrupted care on chronic and subacute conditions, who is taking care of the fifth wave?

\section{Conclusion}

It is important to me to highlight a few points to put this article into the right context.

First, I am well aware that it is a privilege to work in a Swiss hospital during this time, meaning not being confronted with existential fears while several other industry sectors and other countries were hit much harder.

Second, I am also well aware that several professional groups in the health care sector, and not only doctors, have accomplished extraordinary achievements during this crisis.

Third, of course, I see it as a unique privilege to have the opportunity to help other people. And the immense accomplishments achieved by the medical employees during this pandemic show that these people are aware of that.

However, the goal of this article was not to discuss the economic and social impacts of this crisis in general, but rather the experience of the subgroup of young Swiss cardiac surgeons during this extraordinary time.

\section{Disclaimer}

This article represents the personal opinion of the author.

\section{Conflict of Interest}

Dr. Koechlin reports grants from Swiss Academy of Science, grants from University of Basel, grants from Freiwillige akademische Gesellschaft Basel, outside the submitted work.

\section{References}

1 Available at: https://www.luzernerzeitung.ch/international/coronain-italien-die-schlimmste-krise-der-nachkriegszeit-ld.1206478. Accessed in May 2020

2 Available at: https://www.who.int/director-general/speeches/detail/ who-director-general-s-opening-remarks-at-the-media-briefingon-covid-19-11-march-2020. Accessed in May 2020

\section{Editors' Commentary}

This is one of three articles written on request and sponsored by the Swiss Society SGHGC/SSCC (Schweizerische Gesellschaft für Herz- und thorakale Gefässchirurgie). The article was decorated with the Special Swiss Young Cardiac Surgeon Award 2020 by the society. It was the aim to give a voice to colleagues afflicted by the COVID-19 pandemic regarding their career in cardiovascular surgery. Accordingly, personal
3 Gaudino M, Chikwe J, Hameed I, Robinson NB, Fremes SE, Ruel M. Response of cardiac surgery units to COVID-19: an internationallybased quantitative survey. Circulation 2020;142(03):300-302

4 Available at: https://www.tctmd.com/news/mystery-missingstemis-during-covid-19-pandemic. Accessed in May 2020

5 Rodríguez-Leor O, Cid-Álvarez B, Ojeda S, et al. Impacto de la pandemia de COVID-19 sobre la actividad asistencial en cardiología intervencionista en España. REC Interv Cardiol. 2020

6 Available at: https://www.dgthg.de/upload/Stellungnahme\%20 DGCH\%20230320.docx.pdf. Accessed in May 2020

7 Available at: https://dgk.org/daten/schreiben_herzmedizin_an_ mdb_karliczek.pdf. Accessed in May 2020

8 Available at: https://www.instagram.com/p/B-QAYKNAngN/. Accessed in May 2020

9 Available at: https://www.facebook.com/Hirslanden/videos/ 265387584619981/. Accessed in May 2020

10 Available at: https://www.pcronline.com/News/Whats-new-onPCRonline/2020/Cardiac-Surgery-and-the-COVID-19-outbreakwhat-does-it-mean. Accessed in May 2020

11 Available at: https://www.sts.org/publications/news-surgeonsview/covid-19-us-perspective. Accessed in May 2020

12 Hassan A, Arora RC, Adams C, et al; Canadian Society of Cardiac Surgeons. Cardiac surgery in Canada during the COVID-19 pandemic: a guidance statement from the Canadian Society of Cardiac Surgeons. Can J Cardiol 2020;36(06):952-955

13 Available at: https://www.mittellaendische.ch/covid-19-analysenvon-prof-dr-med-dr-h-c-paul-robert-vogt/covid-19-eine-zwischenbilanz-oder-eine-analyse-der-moral-der-medizinischen-faktensowie-der-aktuellen-und-zukünftigen-politischen-entscheidungen/. Accessed in May 2020

14 Available at: https://www.euroelso.net/covid-19/covid-19-survey/. Accessed in May 2020

15 MacLaren G, Fisher D, Brodie D. Preparing for the most critically ill patients with COVID-19: the potential role of extracorporeal membrane oxygenation. JAMA 2020;323(13):1245-1246

16 Zhou F, Yu T, Du R, et al. Clinical course and risk factors for mortality of adult inpatients with COVID-19 in Wuhan, China: a retrospective cohort study. Lancet 2020;395(10229):1054-1062

17 Thamman R, Gulati M, Narang A, Utengen A, Mamas MA, Bhatt DL. Twitter-based learning for continuing medical education? A new perspective for a paradigm shift in medical education, accelerated by COVID-19. Eur Heart J 2020;0:1-3. Doi: 10.1093/eurheartj/ehaa346

18 Available at: https://www.swissinfo.ch/ger/sommaruga-fuerlohndiskussion-in-pflege-kitas-und-detailhandel/45715628. Accessed in May 2020

19 Available at: https://www.tagesanzeiger.ch/pflegefachleute-fordern-covid-zulage-819034750601. Accessed in May 2020

20 Available at: https://www.blick.ch/news/schweiz/am-freitag-um12-30-uhr-sagt-auch-die-schweiz-danke-applaus-in-ganz-europafuer-die-helden-in-weiss-id15802361.html. Accessed in May 2020

21 Available at: https://www.welt.de/vermischtes/article207342165/ Stars-wie-Lady-Gaga-geben-Konzert-fuer-Corona-Helfer-im-Livestream.html. Accessed in May 2020

22 Payne LM. “Guérir quelquefois, soulager souvent, consoler toujours". BMJ 1967;4(5570):47-48

experience is reported for which it is futile to seek peer review.

ThCVSReports therefore presents to you authentic OPINIONS. Discussion in the form of Letters to the Editor is very welcome because this topic still raises more questions than we have currently answers for.

Editors,

Bernd Niemann and Markus K. Heinemann. 